\title{
Vigilancia estatal y represión extraterritorial de la dictadura chilena en la Argentina democrática $(1983-1988)^{1}$
}

\section{State surveillance and extraterritorial repression of the Chilean dictatorship in democratic Argentina (1983-1988)}

Soledad Lastra ${ }^{2}$

\section{Resumen}

Este artículo examina las acciones de inteligencia y represión hacia los exiliados chilenos en Argentina que se realizaron entre 1983 y 1988 por parte de agentes y fuerzas de seguridad chilenas. Junto a ello, busca caracterizar las experiencias represivas vividas por la comunidad exiliada en Argentina y comprender cómo se nutrió la representación de una «amenaza trasandina» que, desde 1986, implicó la multiplicación de distintas caras del control y la vigilancia. Este trabajo se apoya en distintos documentos estatales, diplomáticos y producidos por agentes de inteligencia, así como en prensa de la época. Su hipótesis es que la existencia de infiltrados y agentes de represión extraterritorial en Argentina tensionó el proceso de pacificación que ambos países llevaban adelante desde 1984 a raíz del conflicto bélico por el Canal del Beagle, insinuando la necesidad de implementar un plan de coordinación represiva a ambos lados de la cordillera.

\begin{abstract}
This article examines the intelligence service and repression actions against Chilean exiles in Argentina that were carried out between 1983 and 1988 by Chilean agents and security forces. Along with this, it seeks to characterize the repressive experiences lived by the exiled community in Argentina understanding how the representation of a «transandine threat» involve the multiplication of different faces of control and surveillance since 1986. this article relies on different sources, diplomatic and intelligence documents, as well as in press notes corresponding to that period of time. The hypothesis of this work indicates that the existence of infiltrators and agents of extraterritorial repression in Argentina strained the process of pacification that both countries had been carrying out since 1984 as a result of the war conflict over the Beagle Channel, and hinted the need to implement a coordination plan repressive on both sides of the mountain range.
\end{abstract}

1 Trabajo recibido el 05/05/2020. Aceptado el 06/07/2020.

${ }^{2}$ Universidad Nacional de La Plata. Universidad Nacional de San Martín. Consejo Nacional de Investigaciones Científicas y Técnicas. Contacto: lastra.soledad@gmail.com 
Palabras clave: inteligencia; represión extraterritorial; exilios; dictadura chilena; transición democrática argentina
Keywords: intelligence service; extraterritorial repression; exiles; Chilean dictatorship; Argentine democratic transition

\section{Introducción}

«Argentina actúa soberanamente y no permite -en su país- la acción de ningún servicio de inteligencia que no sean los propios. Ningún servicio de inteligencia de ningún país tiene vía libre en Argentina». ${ }^{3}$ Estas palabras fueron enunciadas a finales de 1988 por Facundo Suárez, titular de la Secretaría de Informaciones del Estado argentino (SIDE). Sus declaraciones buscaban clarificar la posición de Argentina ante las múltiples denuncias presentadas por los organismos de derechos humanos chilenos sobre el accionar clandestino de agentes de inteligencia que perseguían y reprimían a los exiliados en nuestro país. Esta situación no era novedosa. Desde inicios del gobierno democrático de Raúl Alfonsín (1983-1989), existieron distintos episodios de vigilancia y represión a los exiliados chilenos, algunos protagonizados también por los servicios de inteligencia argentinos.

Este artículo se propone examinar las acciones de vigilancia estatal y represión extraterritorial hacia los exiliados chilenos en Argentina que realizó la dictadura chilena entre 1983 y 1988. Desde allí, se abordarán dos cuestiones relacionadas. Por un lado, se busca comprender esas experiencias a la luz de la creciente conflictividad política y social que se vivió en Chile desde 1983. Por otro lado, se interesa por identificar y explicar en qué consistió la preocupación compartida por ambos países sobre la gestación de una «amenaza trasandina» que, desde 1986, generó tensiones en torno a una posible cooperación bilateral de la represión.

Nuestra investigación se inscribe y dialoga con distintos campos de producción de conocimiento sobre la historia reciente del Cono Sur. En primer lugar, asume el desafío de analizar históricamente los años ochenta, yendo más allá del período tradicionalmente delimitado por los estudios de la historia reciente que culmina en diciembre de 1983 con la asunción de Raúl Alfonsín y el regreso de la democracia. Si bien contamos con renovados análisis que desnaturalizan las fronteras tajantes que

\footnotetext{
${ }^{3}$ «Réplica de Facundo Suárez a «derechos humanos» en Chile», Crónica, 30/11/1988, en Mesa Entidades Varias (EV), Legajo 576. Archivo DIPPBA.
} 
se construyeron entre dictadura y democracia, ello no se tradujo aún en esfuerzos sistemáticos por reconstruir el período ni por hacerlo en una clave conectada con otras historias del Cono Sur (Franco, 2019; Velázquez Ramírez, 2019). En ese sentido y, en segundo lugar, nuestro trabajo busca contribuir a los estudios sobre la violencia política y la represión estatal que examinan las coordinaciones represivas regionales y otros hechos de represión extraterritorial, teniendo en cuenta la actuación conjunta y la colaboración diplomática entre distintos gobiernos (Águila, 2018; Fernández Barrio, 2018; Mc Sherry, 2009; Serra Padrós y Slatman, 2014). En el caso de la represión a los exiliados chilenos, los análisis se han restringido al período de creciente autoritarismo del último gobierno peronista y posteriormente de la dictadura militar argentina (1974-1983) (Azconegui, 2020; Casola, 2017; Gatica, 2013; Paredes, 2007), evidenciando la ausencia de investigaciones rigurosas sobre la dinámica represiva en la democracia inaugurada en 1983.En este sentido, nuestro trabajo se encuadra en una zona incómoda pues en última instancia se pregunta por las acciones que una dictadura (Chile) pudo realizar en el territorio de una reciente democracia (Argentina).

Por último, nuestro estudio se enmarca en una agenda de problemas sobre los exilios políticos del Cono Sur que reconoce en la represión regional y extraterritorial un mecanismo de silenciamiento, control y en algunos casos de aniquilamiento físico de la oposición política. En los años ' 70 , las conexiones represivas se vieron favorecidas por la hermandad ideológica en torno a la Doctrina de la Seguridad Nacional y, sobre todo, por un hecho novedoso producido por el exilio masivo de la segunda mitad del siglo XX: su influyente activismo humanitario y la persistencia de algunos proyectos revolucionarios (Franco, 2008; Jensen, 2018; Rojas Mira y Santoni, 2013; Sznajder y Roniger, 2013). En efecto, los estudios que han abordado a los exilios políticos desde su experiencia represiva nos han permitido identificar la sinergia regional de ciertas dinámicas dictatoriales y los diferentes ritmos represivos que cada caso fue teniendo en el marco de estrategias supranacionales. Sobre el Plan Cóndor, por ejemplo, las investigaciones más recientes han reconocido que las conexiones represivas entre los países del Cono Sur tuvieron historias bilaterales propias, lo que nos obliga a considerar los intereses específicos de cada gobierno en planes represivos regionales (Slatman, 2016). ${ }^{4}$ Sin embargo, nuestro artículo no pretende realizar una historia

\footnotetext{
${ }^{4}$ Además del denominado Plan Cóndor, la coordinación represiva entre Chile y Argentina
} 
de la coordinación represiva desde ese momento hasta finales de los años '80 ni busca reconstruir los cambios y continuidades de esas conexiones represivas en ese período. Su objetivo se limita a problematizar la presencia de agentes de inteligencia chilenos en Argentina, tratando de comprender cómo fueron las acciones de vigilancia y represión, en qué aspectos fueron cambiando a lo largo del gobierno de Alfonsín y cómo ellas generaron tensiones políticas entre ambos gobiernos. ${ }^{5}$

Nuestra interpretación es que, entre 1983 y 1988, la dictadura chilena encabezada por el General Pinochet desarrolló distintas acciones de vigilancia y represión hacia los exiliados chilenos en Argentina, generando tensiones en el proceso de paz de ambos países y obteniendo respuestas mayormente «prescindentes» por parte del gobierno de Raúl Alfonsín.

Como veremos, entre 1984 y 1985 inclusive se produjeron en Argentina distintas acciones de vigilancia y algunos hechos aislados de represión clandestina a refugiados y organizaciones del exilio activas en la denuncia de los crímenes de la dictadura de Pinochet. A partir de 1986, la vigilancia se profundizó en torno a lo que en este trabajo llamaremos la «amenaza trasandina», representada por el activo papel que fueron teniendo las organizaciones revolucionarias, en particular el Frente Patriótico Manuel Rodríguez (FPMR). Esta segunda etapa, de 1986 a 1988, se caracterizó por una mayor injerencia de las fuerzas de seguridad chilenas en territorio argentino y por la insinuación de la necesidad de crear un plan de cooperación represiva, lo cual tensionó el horizonte de pacificación en torno al Beagle.

Con respecto a las fuentes consultadas, en primer lugar, recurrimos a documentos producidos por la Cancillería Argentina y por la embajada argentina en Santiago de Chile, correspondientes al Fondo de América del Sur y ala Dirección de Comunicaciones (MRECIC). También del Archivo MRECIC, recuperamos y analizamos las actas y apuntes del Comité de Elegibilidad para los Refugiados (CEPARE), agencia estatal que funcionó desde 1985 en Buenos Aires otorgando el estatuto de refugiado a los chilenos que así lo solicitaran. Estos documentos nos permitieron identificar algunos hechos represivos y la presencia de agentes

puede rastrearse desde el encuentro producido entre Perón y Pinochet en 1974 y, sobre todo, desde septiembre de 1974 con el asesinato del Gral. Carlos Prats en Buenos Aires que fue ejecutado por la Dirección Nacional de Inteligencia (DINA).

${ }^{5}$ Agradezco especialmente las recomendaciones de los evaluadores sobre este punto. 
de inteligencia en Argentina. En segundo lugar, trabajamos con informes producidos por la Dirección de Inteligencia de la Policía de la Provincia de Buenos Aires (DIPPBA) que conserva una rica información sobre el accionar de la comunidad chilena exiliada y sobre la intervención de las fuerzas de seguridad pinochetistas sobre todo en territorio bonaerense. Ello nos permite introducir la aclaración de que esta investigación no se construye sobre información producida por los servicios de inteligencia y las fuerzas de seguridad chilenas, pues su acceso es restringido. De manera que nuestra interpretación deberá ser oportunamente revisada o enriquecida cuando la política sobre los archivos en Chile se modifique. Por último, consolidamos este análisis con relevamiento de prensa chilena y argentina para el período mencionado.

Este artículo se estructura en tres partes. En la primera parte, recorremos los principales hechos y conflictos que incidieron en que, en la transición a la democracia, Argentina se convirtiera en tierra de refugio y de vigilancia. En la segunda parte, analizamos cómo fue la presencia de agentes de inteligencia chilenos desde la recuperación de la democracia en Argentina hasta 1985, tratando de observar matices y complejidades para su comprensión. En tercer lugar, nos concentramos en los años de 1986 a 1988 para interrogar las representaciones construidas sobre una posible «amenaza trasandina»y las respuestas ensayadas por los gobiernos de ambos países. En el cierre, ofrecemos algunas conclusiones.

\section{La Argentina de los '80: territorio de refugio y represión}

A partir de la mediación papal y de la recuperación de la democracia en Argentina, la resolución del conflicto del Beagle permeó la relación del gobierno alfonsinista con la dictadura chilena. El Tratado de Paz y Amistad firmado el 18 de octubre de 1984 -que entró en vigor en 1985- significó un hito para las relaciones bilaterales pues concretó distintos acuerdos comerciales y de intercambio cultural que nutrieron el proceso de pacificación. ${ }^{6}$ Estos acuerdos se situaban por fuera de la naturaleza de los regímenes políticos de cada país y fueron defendidos por

\footnotetext{
${ }^{6}$ El tratado implicó la puesta en marcha de la Comisión binacional de Cooperación Económica e Integración Física (art. 12) y de la Comisión Permanente de Conciliación argentinochilena (art.1) (Memoria de trabajo de 1985, Embajada argentina en Chile, 19/2/1986. MRECIC).
} 
Alfonsín, Pinochet y sus funcionarios como bases fundamentales de un futuro prometedor. ${ }^{7}$

Ahora bien, las relaciones entre Chile y Argentina pueden leerse desde otra óptica cuando consideramos la presencia creciente de exiliados y refugiados chilenos en nuestro país. Entre 1983 y 1987, la magnitud de chilenos que llegaron a la Argentina creció por distintos motivos. Por un lado, porque muchos chilenos que estaban viviendo sus exilios en Europa y en otros países de América Latina, aprovecharon la democratización en Argentina para «acercarse» y esperar a que se concretara la transición chilena. Ello implicó que, de algún modo, estuvieran sometidos a los mecanismos de apertura y clausura que fue utilizando la dictadura para gestionar sus ingresos al territorio chileno (Lastra, 2017). Por otro lado, se produjeron nuevas expulsiones desde Chile, ya sea por medio de sanciones oficiales o bien, en el marco de la creciente violencia que vivió el país en los años ochenta. Esto último se enmarcó en el desarrollo de las Jornadas de Protesta Nacional que, entre 1983 y 1986, convocaron a importantes sectores sociales a manifestarse contra la dictadura militar y que fueron duramente respondidas por las fuerzas de seguridad. ${ }^{8}$

Como señalan Igor Goicovic Donoso (2014) y Rolando Álvarez Vallejos (2011), las jornadas de protesta dieron impulso a la lucha de las organizaciones revolucionarias chilenas que, de distinta manera, desplegaron un importante trabajo territorial para su ejecución. Como efecto de la represión del régimen, se fueron produciendo nuevos exilios de dirigencias y militantes de esas organizaciones, y de jóvenes sin adscripciones políticas claras, que se identificaban como estudiantes y trabajadores.

Quienes arribaron a la Argentina fueron desplegando distintas estrategias de activismo y lucha antidictatorial. Además de los militantes del Movimiento de Izquierda Revolucionario (MIR), del MAPU Lauta-

\footnotetext{
${ }^{7}$ Por ejemplo, algunos títulos fueron «Pinochet destacó el acuerdo del Beagle» (Clarín, 3/ 01/1985); «Alfonsín recalcó necesidad de integración a todo nivel» (El Mercurio, 20/12/ 1985); «Vivamos la paz chileno-argentina» (La tercera de la Hora, 22/4/1986); «Elogia el canciller de Chile» (Clarin, 30/07/1986).

${ }^{8}$ Las Jornadas de Protesta Nacional se iniciaron en 1983 como parte del activismo sindical chileno, al que posteriormente se sumaron otras ramas ciudadanas, gremiales y políticas en torno al reclamo por una salida política y electoral inmediata. Implicaban distintos repertorios de acción que, en general, involucraban la toma de calles y espacios públicos, caceroleos, etc.
} 
ro y especialmente del FPMR creado en 1983 como el brazo armado del Partido Comunista de Chile (PCCh); la DIPPBA registró hacia 1984 la creación de las organizaciones Chile Democrático y del Comité de Solidaridad con Chile, espacios que se articularon con otros actores del campo político argentino. Como veremos, posteriormente ello incidió en la lectura que los servicios de inteligencia construyeron sobre los exiliados chilenos y sobre su capacidad de articular una nueva lucha a nivel regional.

La recepción del gobierno argentino ante estos «nuevos» exiliados fue diferente a la de los años ' $70,{ }^{9}$ pues desde abril de 1985se creó el CEPARE para ofrecer su reconocimiento legal como refugiados. Este organismo radicado en la Cancillería argentina actuó junto a la Dirección Nacional de Migraciones y otras agencias estatales, evaluando las condiciones de ingreso de los extranjeros que podían estar sustentadas en el temor de ser perseguidos por razones políticas, de raza o religión. Los chilenos fueron los que mayor demanda generaron sobre el CEPARE por lo menos hasta 1988, año en que se decretó una ley en Chile que clausuró formalmente las condiciones represivas que producían sus exilios. Como señalamos en otro trabajo, esta agencia fue central para el gobierno argentino pues lo situó en un lugar protagónico dentro del campo humanitario regional al reemplazar al ACNUR en su rol protector de los migrantes y refugiados que llegaban al país (Lastra, 2020).

En ese escenario, si el activismo y el malestar de los chilenos fue creciendo adentro y afuera de Chile, también lo hizo el accionar represivo de la dictadura chilena. Así, en 1983 se creó la Dirección de Comunicaciones de Carabineros (DICOMCAR), organismo de inteligencia y contrainsurgencia de Carabineros que funcionó -en algunos casos con la contribución de agentes de otras ramas de seguridad- profundizando la represión en las Jornadas de Protesta Nacional. Mientras que la Central Nacional de Inteligencia (CNI) -creada en 1977 en reemplazo de la Dirección de Inteligencia Nacional (DINA) - incrementó sus poderes represivos a partir de la Ley Antiterrorista en 1984 (Ley $\mathrm{N}^{\circ}$ 18.314) que la facultó para realizar detenciones sin la orden de un tribunal. Salazar (2012) subraya que entre 1984 y 1987 la CNI «permaneció sumida en una frenética espiral represiva, intentando frenar con las balas, las tortu-

\footnotetext{
${ }^{9}$ La recepción que el gobierno de Juan Domingo Perón y posteriormente de Isabel Perón brindaron a los exiliados chilenos en Argentina estuvo marcada por una creciente criminalización política y actos de detención y persecución (Azconegui, 2020).
} 
ras y el terror lo que no pudo conseguir a través de las labores de inteligencia» (p.190).

En cuanto a la vigilancia exterior, Policzer (2017) ha planteado que, si la DINA se había propuesto eliminar a los exiliados, la CNI en cambio buscó contenerlos y controlarlos, utilizando principalmente a las embajadas como medios de infiltración y espionaje (p. 118-119). Sin embargo, nuestra investigación arroja significativos casos de amedrentamientos físicos y torturas que podían ir más allá de ese propósito de «control» mencionado por este autor.

Desde 1986 en adelante, la situación política interna de ambos países fue altamente conflictiva. En Chile, se produjo una avanzada de la izquierda a través de atentados y acciones violentas que implicaron un endurecimiento de la represión. Mientras que, en Argentina, el conflicto político se profundizó con la sanción de las leyes de Punto Final (1986) y Obediencia Debida (1987) que frenó el juzgamiento de los crímenes cometidos por la dictadura militar y evitó la punición a todo el escalafón de las Fuerzas Armadas. Este proceso de creciente impunidad se agravó con el sostenimiento de la prisión política y la creación de nuevas causas sobre ex militantes del campo político de las izquierdas, algunos de ellos retornados del exilio, aspecto que fue públicamente denunciado por los organismos de derechos humanos locales (Lastra, 2016). El descontento ante la judicialización de la militancia se agudizó con los alzamientos de militares carapintadas (1987 a 1990) y con la fuerte recesión económica que marcó una crisis inflacionaria sin precedentes. Desde entonces, se temió por la fragilidad del horizonte democrático en Argentina y por un rebrote de la «subversión» y un nuevo golpe militar. Estos giros vividos en Argentina en los años posteriores al Juicio a las Juntas Militares (1985) y que no han sido aún rigurosamente investigados, nos permitirán comprender los temores latentes de dos gobiernos atravesados por las huellas de la violencia política y la «amenaza subversiva».

\section{Vigilancia en los '80 sobre el activismo del exilio chileno}

En 1984 los servicios de inteligencia argentinos notaron que las organizaciones chilenas con mayor actividad en el país estaban vinculadas al campo de los derechos humanos y al de las organizaciones de izquierda. Los primeros sobresalían por su accionar de propaganda en villas de emergencia y barrios periféricos, buscando ayuda para los dete- 
nidos en Chile, para crear comités de apoyo por la democratización y «agitar la cuestión inherente a los derechos humanos en aquel país». ${ }^{10}$ De las organizaciones de izquierda, se subrayaba al FPMR que preocupaba por su «virulencia» y su trabajo de reorganización pues estaba convocando a los exiliados chilenos a engrosar «los cuadros combatientes (o) formar células de apoyo a la guerrilla en ese país» a la vez que entraba en contacto con militantes del Ejército Revolucionario del Pueblo (ERP), algunos de «comprobado perfil subversivo». ${ }^{11}$

Por esas fechas, en Chile, Carabineros y la CNI continuaban ejecutando distintos asesinatos y desapariciones a militantes del MIR y el FPMR, algunos ocurridos en enfrentamientos callejeros y otros rigurosamente planificados. Así, el año 1985 se caracterizó por un importante despliegue represivo en Chile que se proyectó también en el territorio argentino.

En enero, por ejemplo, se produjeron dos episodios de requisas, golpes y persecución a exiliados chilenos en Buenos Aires por parte de la CNI que fueron denunciados públicamente. En la prensa se visibilizó que «los amedrentamientos a los refugiados chilenos en diversos hoteles, no han cesado [y que] una vez más ha quedado demostrado cómo la represión que la dictadura ejerce contra su pueblo no tiene fronteras». ${ }^{12}$ Las denuncias se multiplicaron y nueve meses después, dos chilenos tomaron las oficinas del ACNUR reclamando por la falta «de las imprescindibles condiciones económicas y de seguridad personal en Buenos Aires». ${ }^{13}$

Por las mismas fechas, se presentó ante el CEPARE la solicitud de un chileno que pedía ayuda para que el Estado argentino facilitara su reasentamiento en un tercer país. Al respecto, los integrantes del CEPARE apuntaron: «teme a la CNI por su información sobre el cementerio de Pisagua». ${ }^{14}$ Así, vemos que la injerencia de la CNI en la persecución a los exiliados parecía ser un denominador común.

\footnotetext{
${ }^{10}$ Informe Actividades de la colectividad chilena, 6/7/1984, Mesa DS, Carpeta Varios (CV), Legajo 22.865.

${ }^{11}$ Informe Actividades de la colectividad chilena, 6/7/1984, Mesa DS, Carpeta Varios (CV), Legajo 22.865 .

12 «Denuncia de agresión a un exiliado chileno», Clarín, 9/1/1985.

${ }^{13}$ «Dos refugiados ocuparon una oficina de la ONU», Clarín, 1/10/1985. Los chilenos de la toma fueron reasentados en otro país (CEPARE, Expte. 120.583-1/85, Actas 28/11/ 1985 y 23/1/1986, MRECIC).

${ }^{14}$ CEPARE, Nota de reuniones, 28/11/1985, MRECIC. En Pisagua funcionó un campo de concentración de prisioneros políticos. Posteriormente, allí se halló una fosa común en
} 
Uno de los hechos más llamativos de estos hechos de represión extraterritorial consistió en el supuesto accionar de Carabineros. En noviembre de 1985, un exiliado chileno en Argentina apoyado por un abogado del ACNUR se presentó en la seccional primera de San Isidro denunciando que seis personas lo habían secuestrado, entre ellos un agente de Carabineros que había sido reconocido por su tono de voz y aspecto físico. Analizando todo el testimonio, los agentes de la DIPPBA, concluyeron:

teniendo en cuenta el número de integrantes del grupo que operó en dicho secuestro (6 individuos), las características narradas por la víctima haciendo identificación clara [como] componente de carabineros chileno, a la luz se desprende que no se trataría de un hecho común sino de una organización con posibles conexiones supranacionales y con intenciones de hacer presiones políticas o psicológi$\operatorname{cas}^{15}$

Sin embargo, la posibilidad de que Carabineros realizara una operación de esa naturaleza resulta extraña. En particular porque esta fuerza se encontraba políticamente debilitada a raíz del asesinato en Chile de los tres militantes comunistas en lo que trascendió como el Caso Degollados. La CNI había ofrecido las pruebas más importantes contra el accionar de Carabineros, por lo cual existía una fuerte desconfianza entre «las dos instituciones coercitivas más importantes del país» (Policzer, 2007, p. 144). Además, como analiza Camilo Vallejos Muñoz (2019), a principios de 1985 Carabineros sufrió una transformación en su dinámica represiva que consistió en un desplazamiento del imaginario guiado por la Doctrina de la Seguridad Nacional hacia cuestiones vinculadas a la seguridad ciudadana. En este sentido, es posible que fueran agentes de la CNI los que actuaron extraterritorialmente en Argentina y que lo hicieran con la colaboración individual de algún ex carabinero u agente de otra fuerza, planteando así la duda sobre el papel orgánico de esa institución en este hecho particular. ${ }^{16}$

donde se habían enterrado los cadáveres de los prisioneros políticos ejecutados y muertos bajo tortura.

${ }^{15}$ Informe policial, Privación ilegal de la libertad y lesiones graves en San Isidro, Mesa DS, CV, Legajo 24344, 11/11/1985.

${ }^{16}$ Agradezco especialmente al Lic. Camilo Vallejos por sus valiosos comentarios a esta discusión. Las afirmaciones aquí sostenidas son de mi responsabilidad. 
La intervención de agentes de seguridad chilenos en Argentina fue una constante a lo largo de los '80, aunque a partir de 1986 esta presencia se reforzó en respuesta al aumento de la actividad política de las organizaciones chilenas. Sobre ello volveremos en el próximo apartado.

Ahora bien, es importante incorporar algunos matices sobre la presencia de agentes chilenos en Argentina, pues no siempre se debió a las acciones de vigilancia y control de «subversivos». De las fuentes consultadas para esta investigación se desprende que en algunos casos esta presencia podría explicarse por «huidas» o por ser ellos mismos objeto de la persecución de la dictadura chilena.

Por un lado, uno de los registros que tenemos sobre esta condición se encuentra en las actas del CEPARE que, a principios de 1986, trató el pedido de refugio de un chileno cuyo relato resultaba confuso:

Los hechos relatados por el interesado, además de muy dudosa verosimilitud resultan contradichos por la propia institución a la que él remite como prueba y en razón de que todas las actividades alegadas no lo hacen considerable un perseguido político del régimen instaurado en el país del cual pretende refugiarse sino, muy por el contrario, lo harian un colaborador estrecho de aquel y las actividades descriptas de ser ciertas, resultan aún dudoso que generen una persecución que lo compulse a buscar refugio ${ }^{17}$

Por otro lado, una anotación del CEPARE, breve y concisa, incluía la posibilidad de que los espías fuesen solicitantes de refugio. Se trató del caso del agente Sepúlveda Bustos, quien habría solicitado refugio en Argentina en 1985. En el CEPARE se registró: «Sepúlveda Bustos Juan Eduardo -ex DINA- ${ }^{18}$ rechazado». ${ }^{19}$

En esa misma línea, el CEPARE recibió una solicitud de refugio por parte de un militar chileno - del que no se consignó su nombre- que justificó su presencia en Argentina por no querer participar en los procedimientos del ejército chileno ya que transgredía sus convicciones. ${ }^{20} \mathrm{Si}$

\footnotetext{
${ }^{17}$ CEPARE, Expte. 127.577-1/85, Acta 20/2/1986, MRECIC. El resaltado es nuestro. ${ }^{18} \mathrm{El}$ nombre se incluyó en el listado de agentes de la DINA publicado por los tribunales de justicia chilenos. Cfr. https://resumen.cl/articulos/listado-completo-de-los-agentes-de-ladina/

${ }^{19}$ CEPARE, Expte. 372-572-4/85, Apuntes de reunión, 8/11/1985, MRECIC.

${ }^{20}$ CEPARE, Expte. 372.977-4/85, Apuntes de reunión del 23/10/1985, MRECIC.En esa misma línea, llama la atención una nota publicada en la prensa argentina en la cual un grupo de militares calificados como «presuntamente desertores» anunciaron explícitamente
} 
bien los documentos del CEPARE no arrojan mayor información sobre estas solicitudes, estos casos resultan atendibles para nosotros a la luz de que fuesen agentes chilenos «huidos» por conflictos internos, sin descartar la interpretación de que, en realidad, hayan intentado actuar como infiltrados en el CEPARE, alegando una condición de persecución que no pudieron comprobar.

Otros casos de agentes en Argentina se pueden explicar por las persecuciones judiciales iniciadas por jueces chilenos o de otros países en busca de información sobre hechos represivos, allanamientos, torturas y asesinatos sin clarificar. ${ }^{21}$ Ello pudo haber desatado acciones de represión extraterritorial dirigidas por las mismas fuerzas de seguridad con el objetivo de impedir que testigos y cómplices de los atentados, rompieran su silencio sobre esos crímenes. ${ }^{22}$

Si bien contamos con un conocimiento indicial sobre estos movimientos hacia el territorio argentino consideramos que, al verlos de forma articulada y coral, afirman la necesidad de complejizar la mirada sobre las fuerzas estatales como un todo homogéneo y de recuperar sus disputas y contradicciones internas.

\section{La «amenaza transandina» y la profundización de la vigilancia (1986- 1988)}

Como adelantamos previamente, la actividad política de los exiliados chilenos en Argentina fue creciendo desde finales de 1983 favoreci-

su paso al FPMR porque estaban «cansados de ser utilizados en la represión de nuestro pueblo». Si bien resulta extraño que militares pertenecientes al régimen de Pinochet adoptaran un giro tan drástico, lo cierto es que el contraste con otras fuentes nos permitiría considerar la factibilidad de estos actos de discordancia y considerar también la heterogeneidad de las fuerzas de seguridad estatales. «Conferencia de prensa de presuntos militares desertores en Chile», Clarín, 08/08/1986. Agradezco especialmente los valiosos comentarios del evaluador sobre este tema.

${ }^{21}$ Por ejemplo, el accionar de los jueces José Benquis y René García Villegas (Policzer, 2017, p. 147). Ello se refuerza con los análisis realizados por Lisa Hilbink (2014, pp. 185-192) en relación a las tensiones internas del poder judicial y a los márgenes de acción de algunos jueces ante los casos Degollados (1985) y Quemados (1986).

${ }^{22}$ Un ejemplo lo podemos encontrar más adelante en el tiempo, con el asesinato del ex agente de la DINA, Eugenio Berríos, cuyo cuerpo apareció en Montevideo en abril de 1995. (La Nación, 14/08/2015. En línea: https://www.nacion.com/el-mundo/conflictos/ militares-condenados-por-la-muerte-del-quimico-eugenio-berrios-ingresan-a-prision-enchile/LQOXJZ6KFVGN5PVIOMPXEK7SLY/story/ ) 
da por la democratización del país y por el apoyo de distintos dirigentes e integrantes de partidos y organizaciones políticas locales. Esta sinergia política se tradujo en una seria preocupación para los gobiernos de Chile y Argentina cuando comenzaron a producirse atentados y acciones violentas por parte de las organizaciones armadas chilenas. Además, éstas fueron respondidas duramente por la CNI, que entre 1986 y 1987 registró más asesinatos y desapariciones que en años anteriores. ${ }^{23}$

En ese contexto, los agentes chilenos redoblaron su trabajo de espionaje en Argentina, ocupándose especialmente de los grupos de exiliados. En ese esfuerzo, fortalecieron en los medios de prensa su mirada sobre el «enemigo terrorista» que se encontraba tras las fronteras.

Por ejemplo, en un extenso reportaje realizado en enero de 1986 por la prensa de Valparaíso, agentes infiltrados en Mendoza afirmaron que militantes del MIR, del PCCh y de la agrupación Chile Democrático se encontraban planificando acciones «terroristas» desde esa provincia. ${ }^{24}$ Señalaron que «la lucha que llevaba adelante el régimen chileno en territorio argentino era muy larga y difícil» pues se trataba de enfrentar a una organización muy bien estructurada y con apoyo internacional. Sin embargo, a la hora de relatar sobre su accionar concreto en territorio argentino, los entrevistados sostuvieron que su trabajo no consistía en «detener al terrorista sino en anularlo [...] pues si los detienen otros ocuparán su lugar y esta vez no sabrán quienes son». ${ }^{25}$

Así vemos que en Chile se transmitía una idea de la infiltración en territorio argentino como control de la información, sin represión física hacia los exiliados. Sin embargo, los relatos y denuncias vistos hasta ahora subrayan todo lo contrario.

Una de las tensiones políticas más fuertes que se desató entre Chile y Argentina, surgió a principios de 1986, a raíz de las declaraciones de algunos funcionarios argentinos en relación con el aumento de la activi-

\footnotetext{
${ }^{23}$ Informe de la Comisión Nacional de Verdad y Reconciliación, 1991, Tomo II, p. 983. En línea: http://www.derechoshumanos.net/lesahumanidad/informes/informe-rettig.htm ${ }^{24}$ Es importante destacar que, desde Mendoza, los chilenos ejercían importantes presiones públicas para poder regresar. Por ejemplo, en esas mismas fechas, se anunció que más de 500 exiliados chilenos radicados en Alemania, Suecia, Noruega, Polonia, Bélgica, México, se habían reunido en esa provincia para proponer un retorno colectivo (Cable 87, 17/01/ 1986, Caja AH0117, América del Sur, MRECIC).

25 «Brigada especial de investigaciones por primera vez entrega conexiones del MIR», «Denuncian acción terrorista en la frontera chilena» (La estrella en Cable 3, 09/01/1986, CONSAR, Valparaíso. Caja AH 0117, América del Sur, MRECIC).
} 
dad guerrillera trasandina contra Pinochet. El canciller argentino Dante Caputo había afirmado que «el territorio argentino no [era] ajeno al apoyo logístico que el Frente [FPMR] requiere para sus operaciones militares», concluyendo que «la crisis es chilena, pero se nos puede venir encima». ${ }^{26}$ En sintonía, el Ministro del Interior, Antonio Tróccoli, había aseverado que Chile podía convertirse en un escenario de la confrontación Este-Oeste y que los «movimientos violentistas» de ese país estaban alimentando a «la subversión» en Argentina. De este modo, los funcionarios planteaban no sólo que existía una incidencia de la actividad guerrillera chilena en las organizaciones argentinas sino que podía haber una colaboración mutua que reactivara el clima insurgente en la región.

Estos dichos generaron mucha molestia en distintos medios de prensa chilenos que respondieron con un reclamo unísono al gobierno argentino: si existía información fehaciente de dicha colaboración «subversiva», se consideraba necesario pasar a una acción coordinada entre los países. Así, La Segunda exigía «la obligación de buscar métodos de cooperación contra la subversión, que no respeta fronteras ${ }^{27}$. Mientras que, frente al «calentamiento de la frontera con Chile», El Mercurio, subrayaba:

sin duda convendría a ambos países que el gobierno argentino redoblase sus esfuerzos para determinar el fundamento real que tal impresión pueda tener. Si desafortunadamente ese apoyo existiese, nada contribuiría más a la seguridad común y al buen entendimiento que una acción enérgica y eficaz para desarticular la conexión subversiva en territorio argentino $[\ldots]$

Eventualmente si la extensión del fenómeno lo aconsejare, se pudiera llegar a considerar alguna forma de colaboración para enfrentar coordinadamente la embestida totalitaria ${ }^{28}$

La insinuación sobre una posible y deseable coordinación represiva trasandina no parece haber ido más allá del discurso mediático. Por ejemplo, ante un tiroteo suscitado en el paso de Jama, la Cancillería argentina recibió una alerta por parte del cónsul general en Antofagasta señalando que «el segundo jefe de Ia Zona de Inspección de Carabine-

\footnotetext{
${ }^{26}$ «Argentina, ¿Huellas del FPMR?», Revista Hoy, 06/01/1986.

27 «Declaración sobre Chile del Ministro del Interior de Argentina», La Segunda, 22/1/ 1986.

${ }^{28}$ «Preocupación Transandina», El Mercurio, 25/01/1986.
} 
ros, Coronel Misindor Velázquez [enfatizó] que la colaboración con la Gendarmería argentina sería útil para evitar el contrabando de armas y el cruce ilegal de la frontera por terroristas». Sin embargo, el cónsul argentino agregaba en su telegrama: «estimo que se trataba sólo de un comentario, y no de una propuesta ni siquiera oficiosa, como si pensara en voz alta de una materia que estaba siendo considerada a otro nivel». ${ }^{29}$

Por su parte, la DIPPBA no parece haber acompañado la hipótesis de la «peligrosidad». Al menos en1986, las múltiples actividades organizadas por Chile Democrático y la Comisión Argentina de Solidaridad con el Pueblo Chileno fueron catalogadas por los agentes argentinos como acciones de poco impacto público. Así fue calificada una marcha ocurrida en Mar del Plata en conmemoración al aniversario de derrocamiento de Allende; ${ }^{30}$ mientras que otro acto realizado en Morón denunciando «la sangrienta dictadura del chacal Pinochet»e invitando a «derrocar al enemigo número uno de nuestro pueblo» fue informado por los agentes argentinos como un evento que convocó a transeúntes y curiosos. ${ }^{31}$ Sin embargo, como veremos, esa imagen de «poca peligrosidad» de la comunidad de exiliados chilenos cambiaría prontamente.

Por esos años existieron importantes operaciones de ingreso de armamento a Chile, así como acciones de sabotaje organizadas por el FPMR, que nutrían las teorías del régimen militar y de los informes que elaboraba Estados Unidos en torno a «un «desborde con características de guerra civil» (Salazar, 2012, p. 204). Efectivamente, el 7 de septiembre de 1986 el FPMR atentó contra la vida de Pinochet poniendo en jaque los pocos espacios de negociación que se habían construido entre la clase política y la dictadura. En Chile se declaró el estado de sitio, se detuvo a los dirigentes de la oposición y se clausuraron todos los márgenes que lentamente había abierto la movilización popular de los años previos (Otano, 2006, p. 39). En ese contexto se endureció el control sobre la oposición dentro y fuera del país, lo que se tradujo en mayores prácticas de inteligencia, infiltración y amedrentamiento. Si bien, como vimos antes, los exiliados en Argentina ya habían vivido experiencias de

\footnotetext{
${ }^{29}$ Consulado en Antofagasta, Nota S 81, 01/04/1986.Caja AH 0117, América del Sur, MRECIC.

${ }^{30}$ Otros informes similares provenían de Bahía Blanca (15/09/1986), Berazategui (09/09/ 1986) y Villa Linch (19/11/1986). DGIPBA, Resumen de información diaria, 12/9/ 1986, Mesa EV, Legajo 576.

${ }^{31}$ Informe Acto Chileno y volantes anexos, Delegación Morón. DGIPBA, Resumen de información diaria, 12/9/1986, Mesa EV, Legajo 576.
} 
secuestro y persecución, desde el citado atentado la infiltración parece haberse tornado más activa. Por entonces, Clarín anunciaba: «Denuncian la existencia en el país de una vasta red de espionaje chileno»:

Con el objetivo de identificar y neutralizar a connacionales sospechosos [los agentes chilenos] simulan ser desde simples refugiados indocumentados, hasta intelectuales o empresarios. Se sabe que residen incluso en condiciones extremadamente precarias en casas de inquilinato marginales, donde moran expatriados, participan en marchas de repudio desplegando carteles contrarios al mandatario chileno, distribuyen panfletos, organizan campañas de repudio o bien frecuentan los círculos intelectualizados y de pequeña burguesía opositora a la junta chilena [...] La misión primordial de estos agentes es la de recopilar datos de inteligencia e informar de inmediato a Santiago sobre el posible accionar de opositores en territorio trasandino a los efectos de neutralizar pero también realizan acciones directas de intimidación, persecución y aún de privación ilegítima de la libertad ${ }^{32}$

La nota agregaba tímidamente que esta presencia de agentes chilenos no implicaba la existencia de una coordinación represiva entre ambos países, lo cual nos permite volver sobre la evidente inquietud que generaba esta posibilidad a ambos lados de la cordillera.

Desde el atentado contra Pinochet, el problema de la acción extraterritorial se amplificó y transformó con más claridad en un juego de vigilancias dobles: por un lado, a partir de la vigilancia de agentes chilenos y argentinos hacia los exiliados; y, por otro lado, con la realización de una «supravigilancia» por parte de los agentes argentinos hacia sus «pares» chilenos.

Con respecto a la vigilancia de agentes argentinos hacia los exiliados, la DIPPBA identificaba para ese entonces una mayor participación de la izquierda armada chilena en Argentina. Por ejemplo, registró la actividad de una supuesta «célula» del MIR que estaba encargada de «hacer fugar de Chile a ciudadanos perseguidos, facilitarles la estadía en ese país o bien favorecerles la salida a otros». ${ }^{33}$ Además, detectó movimientos de colaboración táctica y de contribución financiera por parte de

\footnotetext{
32 «Denuncian la existencia en el país de una vasta red de espionaje chileno»,Clarín, 15/11/ 1986.

${ }^{33}$ DCI, Detención de Luis Gi Soto Pérez y otros en Capital Federal, 24/09/1986.Mesa DS, CV, Legajo 22245.
} 
agentes cubanos a la comunidad chilena en Buenos Aires, lo que fue calificado como una «incitación política subversiva de los chilenos radicados en Argentina». ${ }^{34}$ En ese sentido, la preocupación de una colaboración mutua se volvía más verosímil para el gobierno argentino que, además, hacia 1987 sufría de una mayor conflictividad política interna por la vigencia de las leyes de impunidad, el mantenimiento de la prisión política de ex integrantes de organizaciones armadas argentinas y la activación de nuevas detenciones a ex Montoneros. ${ }^{35}$ En ese escenario, Facundo Suárez afirmó que Argentina cumplía con un estricto «control preventivo» vigilando a los chilenos, pero sin que ello significara «persecución ideológica» (Clarín, 01/02/1987).

Este «control» no era menor, pues expresaba una genuina preocupación del gobierno radical hacia afuera y hacia dentro del país. Por entonces, Raúl Alfonsín, reconocía esta trama de fuertes tensiones por las que atravesaba Argentina pero planteaba la necesidad de sostener una actitud «prudente» en su relación con Chile, sin involucrarse en sus problemas internos y sin alentar tampoco el accionar de las organizaciones armadas. Mantenía así una misma postura ante la violencia política de cualquier signo, declarándose opositor al accionar del FPMR y a favor de que la democracia chilena se alcanzara por medio de las alianzas entre partidos y no por presiones de otro orden. ${ }^{36}$

Con respecto a la «supravigilancia» que los agentes argentinos ejercían sobre los agentes chilenos, el mismo Suárez informó que efectivamente había espías de la CNI chilena detenidos por la justicia argentina y que esas detenciones se habían producido no por sus actos de inteligencia o espionaje sobre las organizaciones armadas sino por hechos de transgresión hacia la comunidad chilena en nuestro país. Afirmaba: «noso-

\footnotetext{
${ }^{34} \mathrm{El}$ informe recuperaba una nota publicada en la revista quincenal Carta Confidencial, titulado «En Buenos Aires una casa de Chile con cimientos cubanos»-aparentemente con fecha 24/06/1987. En la nota se refería a la creación de la Casa de Chile en la Ciudad de Buenos Aires y del Programa radial «Vamos Chile» como espacios de gestación del germen subversivo (DCI, Policial 744, Mesa DS, CV, Legajo 26233).

${ }^{35}$ En este caso en particular, el CELS había denunciado el procedimiento irregular, «con personas vestidas de civil, con vaqueros y remeras, que dijeron pertenecer a la Policía Federal y que no mostraron las credenciales judiciales» («Detienen a acusados de Montoneros», Clarin, 27/02/1987).

${ }^{36}$ Sobre este tema, ver las declaraciones de Alfonsín en Giussani (1987). Como se analizó en un estudio previo, este posicionamiento ante la violencia política permeó gran parte de las disputas y tensiones que tuvo el CEPARE ante la recepción de los refugiados (Lastra, 2020).
} 
tros no podemos permitir que se ejerzan actos policiales con ciudadanos que están respaldados por la Constitución en Argentina». ${ }^{37}$

Un último momento de vigilancias múltiples se produjo en ocasión del plebiscito celebrado en Chile en 1988, en donde se puso en juego la continuidad o no de Pinochet en el poder. Si bien un mes antes del plebiscito, Pinochet sancionó el Decreto Supremo Exento número 303 (01/09/1988) que anulaba todas las barreras legales para retornar del exilio, ello parece no haber significado un gran alivio para el régimen. En su lugar, se incrementaron las comunicaciones entre el Ministerio de Relaciones Exteriores chileno con el gobierno argentino, lo cual impactó en el relevamiento de escuchas e informes sobre los exiliados que, de acuerdo a los agentes argentinos se encontraban cooptando militantes en los barrios de Buenos Aires para intervenir el día de las elecciones. ${ }^{38}$

En esa coyuntura se produjeron detenciones y nuevos hechos de persecución a los exiliados por parte de los agentes argentinos y chilenos. En julio la policía argentina detuvo en Escobar a cinco chilenos acusados de pertenecer al FPMR ${ }^{39}$ y dos meses después a dos chilenos y un argentino en Mar del Plata. Estos hechos fueron denunciados por los partidos políticos de izquierda, del peronismo y de organizaciones de derechos humanos locales -como Madres de Plaza de Mayo y el Centro de Estudios Legales y Sociales- que realizaron marchas, declaraciones públicas y actos de repudio «por la libertad de los presos políticos de Chile y Argentina». ${ }^{40}$ Este hecho habilitó a que el Partido Obrero denunciara públicamente al gobierno de Alfonsín como un aliado y cómplice de la dictadura chilena. ${ }^{41}$

De forma paralela, se multiplicaron las denuncias ante el ACNUR y la justicia argentina sobre secuestros y torturas ocurridas en Buenos Aires por parte de grupos comando de la dictadura de Pinochet. ${ }^{42}$ Como explica Mónica Gatica para el caso de Chubut, la presencia de «sapos» pertenecientes a la CNI chilena, pero también a la Marina y al Ejército argentino, fue detectada y denunciada por los exiliados en esa región entre 1988 y 1989 (Gatica, 2013, p. 225-226). De manera que, aunque sabemos muy poco sobre las tramas locales y provinciales de esa acción

\footnotetext{
${ }^{37}$ «Está desmantelado el aparato conspirativo», Clarin, 01/02/1987.

${ }^{38}$ Informe Inteligencia, Mar del Plata, 23/9/1988, Mesa DS, CV, Legajo 26233.

${ }^{39}$ Crónica, 29/9/1988 en Mesa EV, Legajo 576.

${ }^{40}$ Clarin, 29/09/1988, Ídem.

${ }^{41}$ Volante, Partido Obrero, 23/9/1988, Ídem.

${ }^{42}$ Clarin, 08/10/1988, Ídem.
} 
extraterritorial, podemos reconocer en estos hechos un anclaje histórico de más largo plazo.

Finalmente, el plebiscito celebrado el 5 de octubre de 1988 contó con un importante operativo de seguridad desplegado por el Ministerio del Interior en Argentina para proteger las sedes consulares. ${ }^{43}$ Ante las numerosas consultas sobre posibles disturbios, las respuestas fueron de tranquilidad y vida normal. Con la victoria del NO al proyecto continuista de Pinochet se reinició la salida política tan anhelada por partidos, movimientos y agrupaciones de chilenos en el exilio. Sin embargo, ello no detuvo la represión. Como compartimos al principio de este artículo, en noviembre de 1988 los organismos de derechos humanos continuaban visibilizando la presencia y accionar de agentes infiltrados. Así, la realidad parecía alejarse bastante de las citadas declaraciones de la SIDE: «ningún servicio de inteligencia de ningún país tiene vía libre en Argentina».

\section{Conclusiones}

La Argentina de la transición a la democracia fue un espacio marcado por la acción extraterritorial de la dictadura chilena. Entre 1984 y 1985 se produjeron infiltraciones, acciones represivas ilegales y amedrentamientos a través de los cuales las fuerzas de seguridad de Pinochet hicieron sentir su presencia ante la comunidad de chilenos exiliados en el país.

Desde finales de 1986 hubo un giro en estas experiencias de vigilancia y represión, pues surgieron importantes tensiones políticas entre los dos países en torno a los alcances del control sobre los exiliados. En ese proceso incidió particularmente el atentado realizado contra Pinochet y el lugar que el FPMR tuvo en ese hecho. Si bien este artículo no ahondó en la militancia del FPMR en Argentina, consideramos que este aspecto merece ser examinado con mayor detenimiento en futuras investigaciones.

La posibilidad de una «amenaza trasandina», constituida por el acercamiento entre distintas organizaciones en Argentina, fue parte de las representaciones que nutrieron el trabajo de los servicios de inteligencia chilenos y argentinos en un juego de dos caras. La primera se

\footnotetext{
${ }^{43}$ Ministerio del Interior, radiograma 5611, 04/10/1988.Ídem.
} 
alimentaba de las alertas construidas por funcionarios argentinos en torno a la cierta «incidencia» que podrían estar teniendo las organizaciones armadas chilenas en los militantes y cuadros de organizaciones argentinas que todavía no se encontraban desactivadas. La segunda cara, se refería al apoyo que el FPMR y otros actores como el MIR, hallaban en Argentina para poder operar militarmente; aval que podía estar dado incluso por la inacción del gobierno argentino ante ese reordenamiento. Para Chile esos temores se comprobaron con el atentado en septiembre de 1986.

A pesar de ello, sostenemos que para ese período no se llegó a definir un plan de coordinación represiva entre los dos países. En su lugar, las respuestas del gobierno argentino parecen haber sido mucho más prescindentes de lo esperado por el gobierno chileno. Del relevamiento realizado no contamos hasta ahora con pruebas concretas que nos permitan pensar que ambos gobiernos se encontraban coludidos en un nuevo «Cóndor» contra la «amenaza trasandina». Si durante los '80 el gobierno argentino esquivó la confrontación abierta con la dictadura chilena tampoco mostró apoyo de otro tipo. Seguramente el proceso de pacificación iniciado por el conflicto del Beagle y los numerosos acuerdos bilaterales que se pusieron en juego en él, incidieron en esta «no intromisión» por parte del gobierno argentino.

Queda mucho más por indagar sobre estas experiencias, reconociendo sus distintas escalas y complejizando sus dinámicas. El problema recorrido aquí sólo forma parte de un universo mayor sobre «los ochenta» que todavía no ha sido suficientemente analizado.

\section{Referencias bibliográficas}

Águila, G. (2018). La represión en la historia reciente como objeto de estudio: problemas, novedades y derivas historiográficas. En G. Águila, L. Luciani, L. Seminara y C. Viano (comps.). La historia reciente en Argentina. Balances de una historiografía pionera en América Latina, pp. 55-72. Buenos Aires, Argentina: Imago Mundi.

Álvarez Vallejos, R. (2011). Arriba los pobres del mundo. Cultura e identidad politica del partido comunista de Chile entre democracia y dictadura 1965-1990. Santiago, Chile: LOM. 
Azconegui, C. (2020). Los refugiados chilenos residentes en Argentina como un «problema de seguridad nacional», 1973-1983. Revista História: Questões \& Debates, Curitiba, v. 68, n. 01, jan./jun, 2020, 171-196. Universidade Federal do Paraná. DOI: http://dx.doi.org/ 10.5380/his.v00i0.00000

Casola, N. (2017). La represión estatal hacia los exiliados chilenos entre 1973 y 1983: La construcción de una legalidad represiva para la expulsión. Estudios, (38), 69-86.

Fernández Barrio, F. (2018). El Servicio Exterior argentino en la represión a la Contraofensiva de Montoneros en Brasil (1978-1980). En D. D’Antonio (comp.). Violencia, espionaje y represión estatal. Seis estudios de caso sobre el pasado reciente argentino, pp. 93-118. Buenos Aires, Argentina: Imago Mundi.

Franco, M. (2008). El exilio. Argentinos en Francia durante la dictadura. Buenos Aires, Argentina: Siglo XXI.

Franco, M. (2019). El final del silencio. Dictadura, sociedad y derechos humanos en la transición (Argentina, 1979-1983). Buenos Aires, Argentina: Fondo de Cultura Económica.

Gatica, M. (2013). ¿Exilio, migración destierro? Trabajadores chilenos en el noreste de Chubut (1973-2010). Buenos Aires, Argentina: Prometeo.

Giussani, P. (1987). ¿Por qué, doctor Alfonsin? Conversaciones con Pablo Giussani. Buenos Aires, Argentina: Sudamericana.

Goicovic Donoso, I. (2014). Temas y debates en la historia de la violencia política en Chile. Contenciosa, 3 (2). DOI: https://doi.org/ 10.14409/contenciosa.v0i3.5070

Hilbink, L. (2014). Jueces y politica en democracia y dictadura. Lecciones desde Chile. México, México: FLACSO México.

Jensen, S. (2018).La historiografía del último exilio político argentino. Itinerarios y desafíos. En G. Águila, L. Luciani, L. Seminara y C. Viano(comps.). La historia reciente en Argentina. Balances de una historiografía pionera en América Latina, pp. 93-108. Buenos Aires, Argentina: Imago Mundi.

Lastra, S. (2016).Volver del exilio. Historia comparada de las politicas de recepción en las posdictaduras de Argentina y Uruguay (1983-1989). Los Polvorines, Argentina: UNGS, UNaM, UNLP. 
Lastra, S. (2017). Dictaduras y retornos del exilio. Chile y Argentina en perspectiva comparada. Clepsidra. Revista Interdisciplinaria de Estudios sobre Memoria, 4 (7), 120-136.

Lastra, S. (2020). El CEPARE, la violencia y otras tensiones políticas del otorgamiento de refugio a chilenos en Argentina (1985-1986). Izquierdas, 49, 3953-3973.

Mc Sherry, P. (2009). Los Estados depredadores: la Operación Cóndor y la guerra encubierta en América Latina. Santiago, Chile: LOM.

Otano, R. (2006).Nueva crónica de la transición. Santiago, Chile: LOM. Paredes, A. (2007), Las condiciones de vida de los exiliados chilenos en Mendoza: 1973-1989, Tesis de Doctorado en Historia. Universidad Nacional de La Plata.

Policzer, P. (2014). Los modelos del horror. Represión e información en Chile bajo la Dictadura Militar. Santiago, Chile: LOM.

Rojas Mira, C. y Santoni, A. (2013). Geografía política del exilio chileno: los diferentes rostros de la solidaridad. Perfiles Latinoamericanos, 21 (41). DOI: 10.18504/pl2141-123-2013

Salazar, M. (2012).Las letras del horror, Tomo II: La CNI. Santiago, Chile: LOM.

Serra Padrós, E. y Slatman, M. (2014).Brasil y Argentina: Modelos represivos y redes de coordinación durante el último ciclo de dictaduras del Cono Sur. Estudio en clave comparativa y transnacional. En S. Jensen y S. Lastra (coords), Exilios: Militancia y represión: Nuevas fuentes y muevos abordajes de los destierros de la Argentina de los años setenta. La Plata, Argentina: EDULP.

Slatman, M. (2016), Dictaduras de seguridad nacional en Chile y Argentina. Estudio comparativo y relacional de sus estrategias represivas. Aletheia, 7 (13)

Sznajder, M. y Roniger, L. (2013).La política del destierro y el exilio en América Latina. Buenos Aires, Argentina: Fondo de Cultura Económica.

Vallejos Muñoz, C. (2019). Carabineros de Chile y la seguridad nacional: una mirada a las representaciones policiales del orden público durante la dictadura, 1973-1990. Revista Historia y Justicia, 13.

Velázquez Ramírez, A. (2019). La democracia como mandato. Radicalismo y peronismo en los ochenta. Buenos Aires, Argentina: Imago Mundi. 